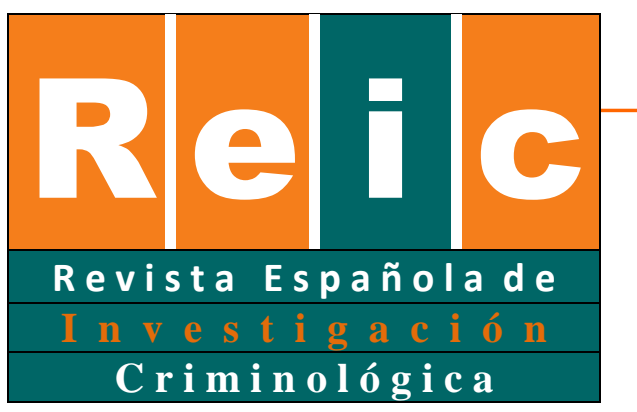

Montoro

\title{
Pedodolls y pedofilia: Límites y evidencias en torno a la utilización de muñecas sexuales con rasgos infantiles
}

\section{Pedodolls and pedophilia: limits and evidence on the use of childlike sex dolls}

\author{
Mónica Montoro ${ }^{1}$ \\ Universidad Pablo de Olavide
}

\section{RESUMEN}

A raíz de la incautación de varias muñecas sexuales con rasgos infantiles en las fronteras de algunos países occidentales, se ha abierto un debate sobre la legalidad de estas muñecas, destinadas principalmente a satisfacer impulsos pedófilos. Algunos sectores arguyen que deberían prohibirse, ante la posibilidad de que fomenten los abusos sexuales a menores; otros alegan que sería recomendable permitirlas ya que canalizarían los impulsos de potenciales agresores. El objetivo del presente trabajo es averiguar si la disponibilidad de estas muñecas promueve la comisión de abusos, dado que no existen hasta la fecha investigaciones sobre el tema. Para ello, se realiza una revisión de la literatura científica sobre pedofilia, pornografía infantil y abusos sexuales a menores, y se incluyen valoraciones de expertos. Los resultados sugieren que la disponibilidad de las muñecas no aumentaría los abusos sexuales a menores por parte de pedófilos, pudiendo incluso llegar a reducir el riesgo de que ocurran.

Palabras clave: pedofilia, muñecas eróticas infantiles, pedodolls, pornografía infantil, abusos sexuales, menores

\section{ABSTRACT}

The recent confiscation of childlike sex dolls in the customs of several Western countries has opened up the debate about these dolls, whose main purpose is the satisfaction of pedophile sexual drives. Some say that the dolls should be banned as they might normalise abuse; others argue that they should be allowed because they act as an outlet for potentially dangerous urges. The aim of this paper is to find out whether or not the availability of these dolls incites

${ }^{1}$ La correspondencia debe dirigirse a: m.montorovelazquez@gmail.com

Revista Española de Investigación Criminológica

Artículo 9, Número 17 (2019)

https://doi.org/10.46381/reic.v17i0.251

WWW.criminologia.net

ISSN: 1696-9219 
abuse, as no studies on this subject have been done yet. For this purpose, we conducted a literature review of pedophilia, child pornography and sexual abuse. Expert opinions are also included. Results suggest that child sex dolls do not increase the risk of real children being abused by pedophiles, on the other hand they may even be able to reduce it.

Keywords: pedophilia, child sex dolls, child pornography, sexual abuse, minors.

\section{Introducción}

\subsection{Objetivos y metodología}

El objetivo del presente trabajo es averiguar si las muñecas sexuales con rasgos infantiles fomentan o no los abusos sexuales a menores por parte de pedófilos. Debido a lo reciente del fenómeno, hoy en día no existen estudios específicos que investiguen la relación entre estos conceptos. De modo que, para aproximarnos al tema de la forma más precisa posible, consideraremos las muñecas sexuales con rasgos infantiles como un tipo de pornografía infantil virtual en tres dimensiones, y utilizaremos estudios que relacionan el consumo de pornografía por parte de pedófilos con la comisión de abusos sexuales a menores.

Para conseguir el objetivo anterior se realizó una revisión bibliográfica que recopila las investigaciones más relevantes sobre la relación entre pedofilia, pornografía infantil y abusos sexuales a menores publicadas hasta la fecha en revistas científicas, disponibles a través de portales electrónicos como PubMed, SageJournal, APA PsycNET, Springer o ResearchGate.

La información disponible cuenta con dos limitaciones principales:

En primer lugar, la mayoría de las investigaciones se centran en el fenómeno de la pedofilia en varones. A pesar de que no hay datos disponibles a gran escala, Seto (2008) revisó varios estudios y concluyó que la prevalencia de la pedofilia podría ser de alrededor del $1 \%$ en hombres, con un máximo del 5\%. Entre mujeres los casos de pedofilia conocidos son escasos, y este fenómeno podría manifestarse de forma distinta, debido a las diferencias entre sexos en cuanto a respuesta y comportamiento sexual (Chivers, Seto \& Blanchard, 2007; Diamond, 2008; Seto, 2008).

Revista Española de Investigación Criminológica

Artículo 9, Número 17 (2019)

https://doi.org/10.46381/reic.v17i0.251

www.criminologia.net

ISSN: 1696-9219 
En segundo lugar, casi todo el conocimiento científico sobre pedofilia proviene del estudio de pedófilos que han abusado sexualmente de menores, y las investigaciones realizadas sobre el tema se basan fundamentalmente en este tipo de literatura.

Lo ideal, indica Seto (2012), sería estudiar la pedofilia basándonos en muestras de pedófilos extraídos al azar de una comunidad antes que de una clínica o una cárcel. Los estudios con pedófilos hallados en estos lugares muestran que entre este colectivo existe una prevalencia mucho más alta de sintomatología psiquiátrica o características antisociales que en el resto de los ciudadanos, lo cual supone un sesgo a tener en cuenta a la hora de investigar y elaborar teorías.

Por otro lado, el estudio de pedófilos que voluntariamente hayan reconocido su condición y no estén relacionados con el ámbito clínico o penitenciario es difícil, dado el estigma social y las crecientes preocupaciones legales y políticas sobre el fenómeno de la pedofilia y los abusos sexuales a menores. Los individuos auto reconocidos como pedófilos estarían arriesgando sus vidas a nivel profesional y social, incluso si nunca han cometido ningún delito contra los menores.

Para averiguar si las muñecas sexuales con rasgos infantiles podrían fomentar o no los abusos sexuales a menores por parte de pedófilos, se siguen los siguientes pasos:

-En primer lugar, se define el concepto de pedofilia y se investiga si está relacionado con los abusos sexuales a menores.

-En segundo lugar, se analizan las características de las muñecas sexuales con rasgos infantiles y la reacción social e institucional a su presencia.

-En tercer lugar, se estudia la relación entre el consumo de pornografía infantil y el abuso sexual a menores.

-Finalmente, se investiga si la pedofilia pudiera considerarse una orientación sexual, con el objetivo de comprender mejor el fenómeno de la pedofilia y las claves para prevenir los abusos sexuales a menores por parte de pedófilos; concretamente, el papel que las muñecas sexuales con rasgos infantiles podrían desempeñar en él.

Revista Española de Investigación Criminológica

Artículo 9, Número 17 (2019)

https://doi.org/10.46381/reic.v17i0.251

WWW.criminologia.net

ISSN: 1696-9219 


\subsection{Definición y características de la pedofilia}

El término pedofilia deriva de las palabras griegas philia, que significa "amor, inclinación a", y pedeiktos "chicos jóvenes" y fue acuñada a finales del siglo XIX por el psiquiatra alemán Richard von Krafft-Ebing (1886).

El Manual Diagnóstico y Estadístico de los Trastornos Mentales (5ª edición, American Psychiatric Association, 2013), en adelante DSM-5, en su página 377 define la pedofilia como una "excitación sexual intensa y recurrente derivada de fantasías, deseos sexuales irrefrenables o comportamientos que implican la actividad sexual con uno o más niños pre púberes, generalmente menores de 13 años". Según el citado manual, para considerar que una persona cumple el criterio diagnóstico debe haber sentido esta atracción durante un periodo mínimo de seis meses, y también es necesario que la misma le haya ocasionado un perjuicio grave en sus relaciones interpersonales o en su estabilidad psicológica, o bien que haya llevado a cabo estos deseos sexuales.

El individuo ha de tener un mínimo de 16 años y ser al menos 5 años mayor que los niños objeto de su atracción sexual -salvo que se trate de un individuo al final de la adolescencia con otro de 12 o 13 años; es necesario en todo caso tener en cuenta la madurez del individuo a la hora de realizar el diagnóstico-.

El DSM-5 especifica que esta atracción por los menores puede ser exclusiva o coexistir con una atracción sexual por individuos adultos; también puede limitarse a uno de los dos sexos, incluirlos a ambos, o sentirse únicamente hacia los menores miembros de la propia familia. Dentro de la pedofilia, también podemos atender a varias subclasificaciones según la edad de los niños objeto de la atracción. La hebefilia define la atracción por individuos pubescentes -13-16 años- y la infantofilia por menores de 5 años.

\subsection{Causas del abuso sexual a menores}

Se considera responsable de un delito de abuso sexual al que realiza actos sexuales con un menor de 16 años, según el artículo 183.1 del Código Penal español. El apartado segundo del mismo artículo castiga a aquellos que realicen dichos actos sexuales empleando violencia o 
intimidación como autores de agresión sexual. A lo largo de estas líneas nos referiremos principalmente a los abusos sexuales, sin hacer una distinción estricta entre tipos penales, dado que el propósito de este trabajo es dilucidar si las muñecas sexuales con rasgos infantiles fomentan los delitos basados en el contacto sexual con niños reales, excediendo del objeto de éste la forma y los medios empleados por los autores para que dicho contacto se produzca.

Es una creencia común que todos los que abusan sexualmente de niños son pedófilos. Sin embargo, el término pedofilia no es un concepto criminológico ni legal, como las agresiones o los abusos sexuales, sino un diagnóstico clínico realizado por un psiquiatra o un psicólogo (Hall, 2007). Se trata, como hemos visto, de un individuo adulto que se siente principalmente atraído por jóvenes prepubescentes.

Beier (2015) indica que solo el $40 \%$ de los abusos sexuales a menores son cometidos por pedófilos, mientras que el $60 \%$ no manifiesta esta inclinación sexual, pero cometen los abusos por otras razones. Según el experto, entre este último grupo podemos encontrar a adolescentes con escasa experiencia sexual que se inician con menores mucho más jóvenes que ellos, personas con discapacidad intelectual, individuos con trastornos antisociales de la personalidad o que fueron víctimas ellos mismos de abusos en la infancia.

\subsection{Diferencia entre los pedófilos que cometen abusos y los que no}

Desde 1980, el foco de la investigación para prevenir los abusos sexuales a menores ha estado en los factores sociales y psicológicos. Una revisión de la literatura disponible sobre el tema desde 1990 concluye que esencialmente los individuos que abusan y agreden sexualmente a menores no difieren de los que atentan contra la libertad sexual de los adultos(Whitaker et al, 2008).

Los principales factores de riesgo en ambos casos son los factores generales para la comisión de cualquier delito. Los factores familiares se encuentran fuertemente relacionados con el abuso sexual a menores, así como con otros comportamientos antisociales y delictivos. Los focos de intervención para los pedófilos podrían, por tanto, ser el desarrollo de habilidades sociales y de gestión emocional, que contribuyen en general a la prevención de delitos.

Revista Española de Investigación Criminológica

Artículo 9, Número 17 (2019)

www.criminologia.net

ISSN: 1696-9219 
Paradise (2001) indica que existe un gran número de pedófilos que fueron ellos mismos víctimas de abuso sexual en la infancia. La falta de apoyo familiar ante este hecho, que a menudo es encubierto para evitar tensiones en el seno de la familia, supone un factor de riesgo para la comisión de abusos sexuales posteriormente por parte de estas personas.

En última instancia, la diferencia entre los pedófilos que delinquen y los que no parece ser la capacidad de estos últimos para controlar sus impulsos. Existe una mayor conectividad entre regiones cerebrales relacionadas con el control de impulsos en los pedófilos que no han cometido delitos que en los que sí los han cometido (Beier et al, 2017). Los sujetos de control -no pedófilos- muestran también ese mayor desarrollo de las zonas del cerebro relacionadas con el control de impulsos, a un nivel similar al de los pedófilos sin antecedentes de abuso sexual.

Estos resultados sugieren que una persona con tendencias pedófilas no va a suponer necesariamente un peligro potencial para los niños, puesto que es su capacidad de control de estos impulsos lo que determina si acabará cometiendo abusos o no.

\section{Debate en torno a las muñecas}

\subsection{Trottla: las muñecas sexuales con rasgos infantiles}

Trottla es una compañía japonesa que fabrica muñecas sexuales diferentes de las tradicionales. En vez de asemejarse a mujeres adultas, sus creaciones representan a adolescentes y niñas mayores de 5 años (no se fabrican muñecas representando a niñas menores de esta edad o bebés), con las proporciones anatómicas correctas, piel suave imitando la humana y con la posibilidad de calentarse para que su temperatura se asemeje a la de una persona real -véaselas Figuras 1 y 2 -.

Shin Takagi, fundador de la compañía Trottla, tomó la decisión de empezar a fabricar sus muñecas en un intento de reconciliar su atracción sexual hacia los niños con la convicción de que éstos debían ser protegidos. Su objetivo es ayudar a los individuos con tendencias pedófilas a expresar sus deseos de forma ética y legal, y con frecuencia recibe cartas de sus clientes -entre ellos médicos, profesores de preescolar e incluso famosos- en las que le 
indican que, gracias a sus muñecas, han podido evitar el cometer un delito (Shin Takagi, citado por Morin, 2016).

En relación con esto, cabría plantearse la existencia de dos tipos de pedófilos (Seto, citado por Morin, 2016). Para unos, el acceso a pornografía infantil artificial o muñecas sexuales con rasgos infantiles puede ayudarles a aliviar sus impulsos sexuales, reduciendo la probabilidad de que busquen pornografía infantil real o contacto sexual con niños. Para otros, tener estos sustitutos únicamente agravaría su frustración y les haría más propensos a cometer abusos. No podemos saberlo, porque todavía no hay estudios concluyentes en esta área, si bien convendría realizarlos cuanto antes, aunque fuese para regular un mercado que parece que sólo acaba de comenzar su andadura.

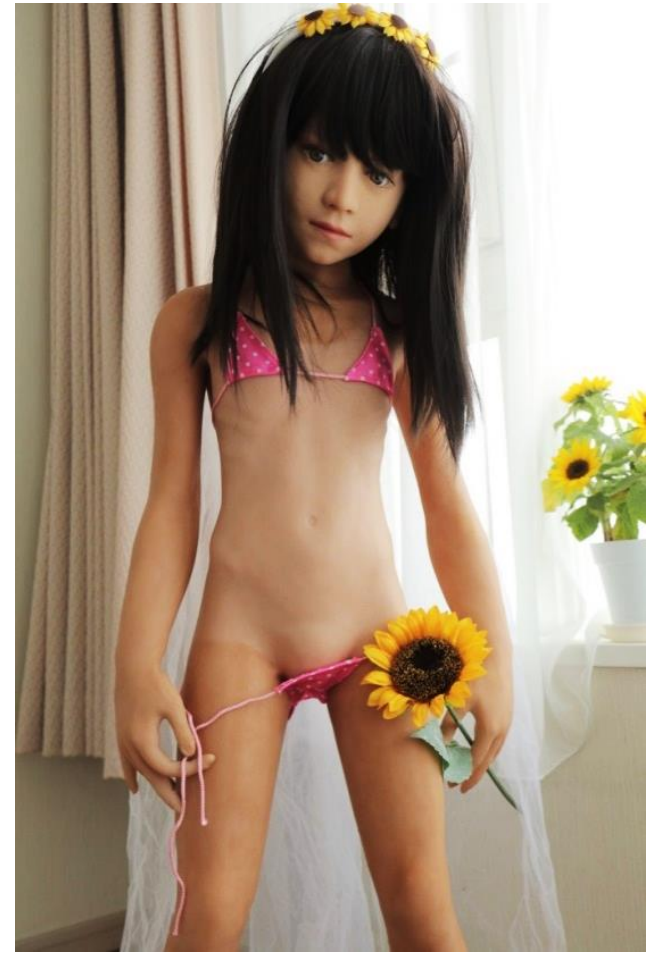

Figura 1: Muñeca en bikini rosa

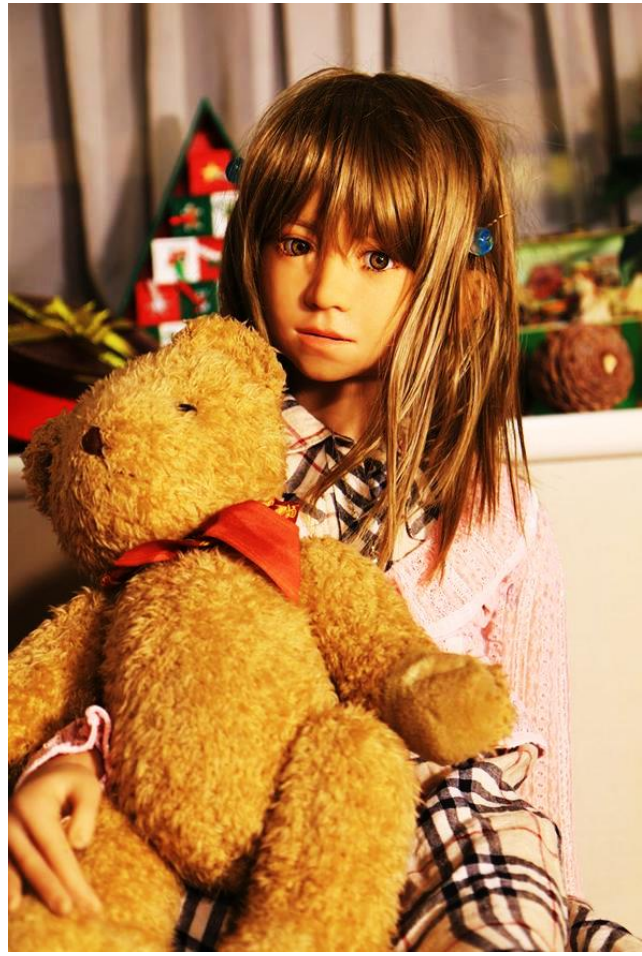

Figura 2: Muñeca con oso de peluche 


\subsection{Los antecedentes de las muñecas sexuales con rasgos infantiles}

A pesar de que Trottla ha sido la primera compañía que comercializa muñecas de este tipo, Takagi no es el primero en fabricarlas ni en mostrarlas al mundo. Tampoco es el primero en afirmar que el propósito de sus muñecas es canalizar impulsos imposibles de materializar en la realidad.

Morton Bartlett y Hans Bellmer fueron dos artistas que, en la segunda mitad del siglo XX, también crearon muñecas representando a niñas prepubescentes. A diferencia de Bartlett, que las presentó en escenas cotidianas revestidas de idealizada candidez -véase Figuras 3 y 4-, Bellmer colocó a sus muñecas, casi siempre desnudas y a menudo desmembradas, en poses retorcidas que aluden a la violencia sexual y el abuso infantil -véase Figura 5-.El propósito de Bartlett al crear sus muñecas era sublimar impulsos que no hubieran podido expresarse de otro modo (Bartlett, citado por Harris, 1994) y el trabajo de Bellmer evidencia deseos pedófilos a la vez que una marcada misoginia (Knight, 2011).

Tanto las obras de Morton Bartlett como las de Hans Bellmer han sido expuestas en galerías y museos de todo el mundo, incluyendo el Museo Metropolitano de Nueva York (Bartlett) y el Museum of Modern Art (Bellmer).

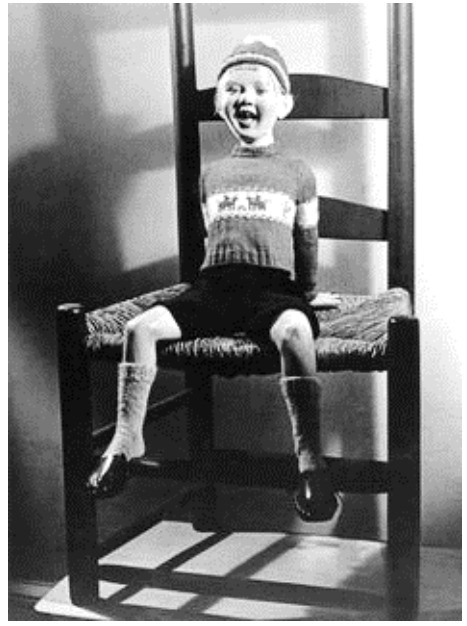

Figura 3: Niño (Bartlett)

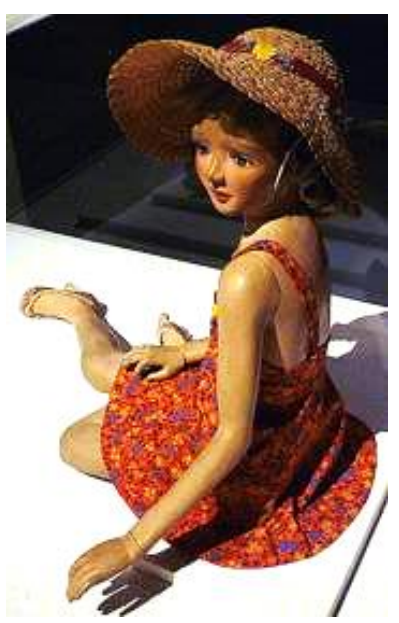

Figura 4: Niña (Bartlett)

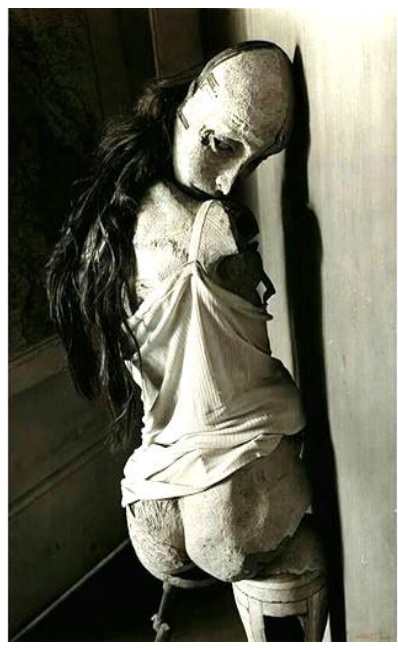

Figura 5: Doll (Bellmer) 


\subsection{Las muñecas Trottla: un debate ético}

Con el rápido avance de las nuevas tecnologías, y especialmente de la inteligencia artificial, pronto las muñecas sexuales con rasgos infantiles, también conocidas como "pedo dolls", podrían dar paso a las "pedo bots". Al margen de la polémica sobre si éstas debieran legalizarse o no, existen ya varias compañías que fabrican robots con finalidad sexual, como AbyssCreations, SweetDolls o la española SyntheaAmatus.

Desde una perspectiva ética, cabría considerar el efecto que dicha permisibilidad podría causar en la moral social, pues actualmente la mera idea de mantener contacto sexual con un menor genera repulsión; además podría contribuir a la deshumanización de quienes más sufren los abusos, como mujeres y niños (Sharkey, Van Wynsbergue, Robbins \& Hancock, 2017).

En una revisión del campo desde la ingeniería robótica, Rutkin (2016) considera que no sólo se debería permitir a las personas tener estas muñecas, sino que debería recetarse como parte de un tratamiento; de este modo servirían como vía de escape para los impulsos pedófilos y los niños quedarían protegidos.

Antes de decantarnos por una u otra tesis, sería recomendable la realización de estudios empíricos al respecto. Sin embargo, esta posibilidad no es fácil de llevar a cabo, dadas las dificultades de encontrar pedófilos dispuestos a participar en el estudio, y por otro lado es probable que varios sectores se opongan a semejante línea de investigación (Darling, citado por Rutkin, 2016).

\subsection{Las muñecas Trottla: un debate legal}

\section{En España}

La progresiva agravación de la expresión punitiva y el gradual adelantamiento de las barreras de protección penal en los delitos de pornografía infantil se deben en gran medida a la asunción de compromisos internacionales por parte de nuestro país, tal como indica la Circular 2/2015 de la Fiscalía General del Estado sobre los delitos de pornografía infantil tras la reforma operada por la LO 1/2015, de 30 de marzo. 
Hasta la entrada en vigor de esta ley, que cumple lo dispuesto por el artículo 5 de la Directiva 2011/93/UE del Parlamento Europeo y del Consejo de 13 de diciembre de 2011, nuestro Código Penal no incluía la pornografía virtual ni la técnica. La pornografía virtual se basa en la elaboración de imágenes artificiales, pero realistas de menores mediante ordenador $\mathrm{u}$ otros medios. La pornografía técnica es aquella que muestra imágenes de adultos aparentando ser menores en un contexto sexual.

El informe del Consejo Fiscal de 8 de enero de 2013 justificó su inclusión argumentando que este tipo de material también contribuye a banalizar y, por ende, aceptar la explotación sexual de los niños; además supone un ataque para la dignidad de la infancia.

La Circular indica que con esta ampliación se puede considerar que se está protegiendo la dignidad e indemnidad sexual de la infancia en general como bien supra jurídico individual. En todo caso, el bien jurídico protegido no sería ni la indemnidad sexual ni la imagen de un menor en particular.

La nueva redacción del artículo 189.1.d) considera pornografía infantil a las imágenes realistas de un menor participando en una conducta sexualmente explícita o a las imágenes realistas de los órganos sexuales de un menor, con fines principalmente sexuales.

Para evitar extensiones indebidas del concepto de pornografía infantil, el concepto de “imágenes realistas” deberá estar sujeto a una interpretación restrictiva. La Circular entiende "realista" como "que trata de ajustarse a la realidad" siguiendo la definición del Diccionario de la Real Academia Española. Imágenes realistas serían aquellas que se aproximan en un alto grado a la representación gráfica de un menor o de sus órganos sexuales, que parecen reales, aunque no lo sean. Este concepto podría incluir imágenes generadas por ordenador o alteraciones de imágenes de personas existentes, y excluye en todo caso los dibujos animados, manga o similares, por no poder considerarse que pretenden acercarse a la realidad.

Probablemente las muñecas Trottla podrían considerarse “imágenes realistas” en 3D, por su alto grado de parecido con los menores reales, a los que tratan de representar, aunque al observarlas puede apreciarse claramente que se trata de muñecos y no de niños reales. Queda pendiente que los Tribunales españoles se pronuncien a este respecto, aunque en España aún no se ha planteado ningún caso. 
A nivel internacional

Desde 2013, los oficiales de las aduanas australianas han confiscado 18 envíos de muñecas sexuales con rasgos infantiles importados desde el extranjero, dado que la legislación australiana considera a estas muñecas como material de explotación infantil (Donnelly, 2016).

Además, más de 60.000 personas han firmado una petición en la web Change.org (Fighters Against Child Abuse Australia, 2015-2016) para que se prohíba la importación de estas muñecas a Australia, alegando que constituyen repugnantes ayudas para pedófilos y atentan contra la sacralidad de los niños.

Si estas muñecas pueden ser consideradas o no pornografía infantil es una cuestión sujeta a debate. En 2013, una de las muñecas fabricada por una compañía japonesa también fue interceptada en un aeropuerto canadiense y el hombre que la solicitó fue arrestado, acusado de poseer pornografía infantil (Revesz, 2016). Este caso abrió el debate en el país sobre si sería necesario actualizar la ley en una etapa de rápido crecimiento tecnológico como el que experimentamos ahora.

En Reino Unido, el solicitante de una de estas muñecas fue declarado culpable por importación de un artículo indecente; es la primera condena de este tipo en Inglaterra (General, 2017). En Noruega sendos cargamentos de muñecas también fueron interceptados y un hombre de 23 años fue condenado, en noviembre de 2017, a seis meses de prisión por haber encargado una muñeca sexual con rasgos infantiles (Taylor, 2018).

Sin embargo, la organización finlandesa-The Finnish Sexpo Fundation(2017)defiende la presencia de estas muñecas, perfectamente aceptadas en países como Dinamarca, argumentando que, al contrario de la creencia popular, no promueven los abusos a menores, sino que suponen una vía de escape moralmente neutra para los impulsos sexuales de potenciales agresores, lo cual protege a los niños ${ }^{2}$.

La cuestión también ha sido planteada en Estados Unidos, con un resultado diferente al de Australia, Canadá o el Reino Unido. Hill (2014) explica que en 2002 el Tribunal

\footnotetext{
${ }^{2}$ Argumento procedente de The Finnish Sexpo Foundation, redactado por su director ejecutivo, Tommi Palaanen
} 
Supremo estadounidense rechazó un proyecto de ley que criminalizaba la creación, distribución o posesión de pornografía infantil virtual. El entonces Gobierno de Estados Unidos argumentó que el material que simulaba ser pornografía infantil dañaba a los niños reales porque contribuía a sostener ese mercado y animaba a los potenciales explotadores de menores.

Sin embargo, el Tribunal Supremo estadounidense se mostró en desacuerdo, indicando que las imágenes pornográficas virtuales, donde el niño es una imagen creada por ordenador o un adulto que parece joven, son legales, sin importar lo realistas que parezcan. Si no se implica a un menor auténtico para su producción, es lícito, concluye. ¿Significa esto que los robots o muñecas de aspecto infantil van a ser legales en Estados Unidos?

A pesar de que las muñecas Trottla llevan vendiéndose globalmente desde hace más de diez años, y han surgido otras compañías similares como la también japonesa Harumi Designs, los tribunales de Estados Unidos, como los de muchos otros países, todavía no se han pronunciado.

En general, nos encontramos con una falta de claridad legislativa sobre si los muñecos y robots sexuales deberían ser vendidos legalmente y qué clase de posesión y uso debería permitirse.

\section{Evidencias}

\subsection{Impacto de la pornografía infantil en los abusos sexuales}

Existe un debate entre los investigadores sobre si el consumo de pornografía infantil influye en la posterior comisión de abusos sexuales a niños. Averiguarlo sería de gran relevancia dado que los resultados podrían ser extrapolables a las muñecas sexuales con rasgos infantiles, las cuales podrían ser consideradas un tipo de pornografía infantil virtual en tres dimensiones.

Una revisión de la literatura existente permite concluir que no queda claro si el consumo de pornografía infantil tiene un impacto causal en los abusos a menores (Fisher, Kohut, Gioacchino \& Fedoroff, 2013). Endrass (2009) examinó las tasas de reincidencia en una muestra de pedófilos durante 6 años. Los resultados obtenidos demostraron que el

\section{Revista Española de Investigación Criminológica}


consumo de pornografía infantil por sí mismo no es un factor de riesgo o predictivo de posteriores abusos a menores. Por otro lado, las edades de inicio en el consumo de pornografía y la frecuencia de su uso es la misma en el caso de autores de delitos sexuales contra adultos, pedófilos, personas con disfunciones sexuales y sujetos control (Condrom \& Nutter, 1988).

Un estudio con consumidores de pornografía infantil durante una media de 4 años reveló que entre los que posteriormente cometieron abusos sexuales a menores, el consumo de pornografía no aparece como factor de riesgo influyente (Eke, Seto \& Williams, 2011). Por tanto, la posibilidad de que este consumo desemboque más tarde en abusos sexuales a niños reales depende de la presencia de otros factores de riesgo. La posesión de pornografía infantil sin un previo historial de abusos sexuales a menores no parece incrementar el riesgo de nuevos abusos, concluye el estudio.

El resultado de estos estudios sugiere que las muñecas sexuales para pedófilos, consideradas como pornografía infantil, no causarían un impacto mayor en la tasa de abusos y agresiones sexuales a menores que aquél que causarían las muñecas sexuales tradicionales en la tasa de atentados contra la libertad sexual a adultos.

Por otro lado, estos estudios han sido realizados a nivel micro, es decir, utilizando muestras reducidas compuestas principalmente por población penitenciaria. Sin embargo, cabría plantearse el efecto que podría tener la legalización de las muñecas en la población general. ¿Se produciría el efecto normalizador que muchos temen y, de repente, muchas personas empezarían a adquirir y utilizar estas muñecas? O, peor aún, ¿se produciría una normalización de las relaciones sexuales con menores y aumentaría escandalosamente el número de abusos?

Un estudio concluye que legalizar la pornografía infantil no solo no aumenta, sino que puede incluso disminuir las tasas de abuso sexual a menores (Diamond, Jozifkova \& Weiss, 2011). Los autores estudiaron la evolución de los delitos contra la libertad sexual en la República Checa cuando el país pasó de tener una estricta prohibición sobre los materiales sexualmente explícitos a una situación donde dichos materiales estaban descriminalizados, incluyendo la pornografía infantil. Analizando estos datos, descubrieron que el número de

\section{Revista Española de Investigación Criminológica}

Artículo 9, Número 17 (2019)

www.criminologia.net

ISSN: $1696-9219$ 
casos de abuso sexual a menores disminuyó significativamente después de 1989, cuando la prohibición se levantó, y no ha vuelto a aumentar.

Los resultados del estudio, replicado con éxito en Canadá, Croacia, Dinamarca, Alemania, Finlandia, Hong Kong, Shangai, Suecia y Reino Unido muestran que, en general, no existe un incremento en los delitos contra la libertad e indemnidad sexuales tras la legalización de la pornografía. Estos hallazgos sostienen la teoría de que la pornografía es utilizada como un sustituto del contacto sexual con menores reales, más que como un incentivo. Los autores del estudio se posicionan totalmente en contra del uso de menores reales en la realización de dicha pornografía, pero sí sugieren que el uso de materiales producidos virtualmente podría tener efectos beneficiosos (Diamond, Jozifkova \& Weiss, 2011).

\subsection{La pedofilia como orientación sexual}

Hall (2007) en su revisión de la literatura concluye que los tratamientos existentes no logran modificar la orientación básica del pedófilo hacia los niños: tras un año de tratamiento combinado de terapia cognitiva y farmacológica, los sujetos todavía mostraban interés sexual en los niños, aunque la intensidad y frecuencia de los impulsos sexuales había disminuido.

Esto lleva a Seto (2012) a plantearse si la pedofilia pudiera ser considerada una orientación sexual y qué influencia tendría esto para la ciencia, la práctica clínica y las políticas públicas. La mayor parte de las personas entiende la orientación sexual aplicada al género: los heterosexuales se sienten atraídos por las personas del género opuesto, los homosexuales por las del mismo género, los bisexuales por individuos de ambos géneros. Sin embargo, podría considerarse la existencia de una orientación sexual con respecto a la edad: los pedófilos se sentirían atraídos por niños, los teleiófilos por adultos y los gerontófilos por ancianos.

Existen razones objetivas basadas en los resultados de diversos estudios que, según Seto (2012), permitirían considerar la pedofilia como una orientación sexual:

En primer lugar, la edad de aparición del interés sexual es similar en los pedófilos y en los heterosexuales u homosexuales. Numerosos individuos diagnosticados con pedofilia 
admiten que empezaron a sentirse atraídos sexualmente por niños antes de alcanzar la edad adulta (Abel et al, 1987; Freund \& Kuban, 1993; Li, 1991; Marshall, Barbaree \& Ecles, 1991).

En segundo lugar, la pedofilia también es estable en el tiempo. Una vez identificada, es posible predecir que persistirá el interés sexual en los niños hasta 40 años después (Hanson et al, 1993).

En tercer lugar, buena parte de los pedófilos no buscan sólo el contacto sexual con los menores, sino también relaciones románticas con ellos; al igual que individuos heterosexuales u homosexuales lo hacen con personas del género opuesto o del mismo, respectivamente. En varios estudios llevados a cabo, los pedófilos describían sus relaciones con los niños como íntimas, afectivas y amorosas, más que meramente sexuales (Li, 1991; Wilson \& Cox, 1983).

Según Seto (2012), este cambio de paradigma conllevaría tres efectos principales:

En lo tocante a la ciencia, las investigaciones posteriores pasarían a centrarse en las posibles causas bioquímicas y neurológicas de la pedofilia -como sucede con la homosexualidad- en vez de en los condicionantes sociales y del desarrollo: abusos sexuales en la infancia o sentimientos de inadecuación social.

En cuanto a la práctica clínica, esta idea cambiaría la aproximación de los psicólogos y psiquiatras a la hora de diagnosticar y tratar la pedofilia. La orientación sexual en función de la edad, como la de género, sería contemplada como algo innato, diagnosticada a partir de autoreportaje, tiempo de reacción y respuesta genital.

Por tanto, también se extendería a la pedofilia el resultado de las terapias reorientativas llevadas a cabo en hombres homosexuales, cuyos resultados sugieren que las intervenciones terapéuticas pueden ser capaces de modificar el comportamiento del individuo o los patrones de activación sexual, aunque sin alterar las preferencias de base (Drescher \& Zucker, 2006). Es decir, si consideramos la pedofilia como una orientación sexual habría que asumir que, al igual que la homosexualidad, no hay manera de modificarla, de modo que las nuevas terapias se fundamentarían en enseñar a los pedófilos estrategias de auto regulación y control de impulsos, más que en tratar de cambiar sus preferencias sexuales básicas. 
En lo concerniente a las políticas públicas, cabría plantearse qué pasaría si las normas de no discriminación por razón de orientación sexual en función del género se extendieran a la orientación sexual en función de la edad.

Por mucho que la sociedad avance, es prácticamente imposible que la pedofilia sea aceptada, dado que sus manifestaciones incluyen las relaciones sexuales con menores, que por su propia naturaleza van a ser siempre consideradas abusivas.

Las relaciones sexuales mutuamente consentidas entre adultos no deben ser objeto de discriminación, de eso no cabe duda. La pedofilia, sin embargo, conllevaría relaciones sexuales entre un adulto y un niño, que son asimétricas. Efectivamente, entre un menor y un adulto existen diferencias sustanciales en habilidades cognitivas, desarrollo psicosexual y anatomía que normalmente no están presentes en las relaciones entre adultos.

Sin embargo, ¿puede llegar a ser aceptada la pedofilia, es decir, reconocer y no temer la existencia de esta inclinación sexual presente en algunas personas, siempre que no vaya acompañada de abusos o agresiones sexuales a los menores?

\subsection{Terapia cognitiva como tratamiento para la pedofilia}

A pesar de que la sociedad, alentada por el sensacionalismo mediático, suele demandar castigos duros para los pedófilos que abusan de menores, Seto (2008) indica que el endurecimiento de las penas no ha servido para reducir las tasas de reincidencia. El autor afirma que para acabar con los problemas asociados a la pedofilia como la explotación sexual infantil (a través de la pornografía infantil, el turismo sexual, la prostitución juvenil, las agresiones y abusos sexuales a menores) es necesaria una visión mucho más comprensiva y menos discriminatoria de los pedófilos.

Actualmente, el tratamiento psicológico y los servicios de apoyo están disponibles principalmente para los individuos que ya han sido condenados por delitos sexuales contra menores. Hay pocos recursos para aquellos pedófilos que no han delinquido y necesitan ayuda para no hacerlo. Por ejemplo, el Dunkenfeld Project en Alemania, que usa campañas publicitarias en medios de comunicación para anunciar servicios terapéuticos para los que se identifiquen como pedófilos. Estudios llevados a cabo por la propia organización con las 
personas que han atendido -más de 400 desde 2005 hasta 2015- demuestran que la terapia reduce el riesgo de comisión de abusos a menores y de consumo de pornografía (Beier, 2015). Su consigna es "nadie es culpable por su orientación sexual, pero todos somos responsables de nuestro comportamiento".

También destacan B4UACT, Don'tOffend y Stop ItNow!, organizaciones que ofrecen servicios terapéuticos confidenciales a los que se auto identifiquen como pedófilos, centrados en el desarrollo de la autoestima y la responsabilidad, la habilidad de resolver los problemas, manejar las emociones y controlar los impulsos sexuales, especialmente en situaciones de riesgo. De esta manera, los usuarios de dichos programas aprenden a llevar vidas plenas y satisfactorias a la vez que se mantienen dentro de la legalidad.

Si los pedófilos, concluye Seto (2008), continúan siendo temidos y odiados por la sociedad, seguirán escondidos, lo que impedirá mejorar la comprensión de la pedofilia y consiguientemente prevenir la explotación sexual infantil.

Esta creencia es compartida en Virtuous Pedophiles, una plataforma online que se diferencia de los anteriores recursos en que está exclusivamente fundada y dirigida por pedófilos. Su propósito es ofrecer apoyo a aquellos que están convencidos de que tener contacto sexual con un niño no es correcto pero que se sienten abrumados por unos impulsos sexuales que no saben bien cómo manejar y que les hacen sentirse culpables, provocándoles problemas de ansiedad, depresión e incluso suicidio (VirtuousPedophiles, 2012). "No somos criminales sólo por tener estos deseos, mientras no actuemos sobre ellos" recalcan desde la página web, pues están firmemente convencidos de que tratar a los pedófilos con respeto y comprensión supone un beneficio tanto para los niños como para ellos. Para los primeros, porque si los pedófilos dejan de tener miedo al rechazo empezarán a buscar más ayuda para controlar sus impulsos. Para los segundos, porque en vez de vivir ocultos, invadidos por fuertes sentimientos de vergüenza y autorreproche, aprenderán a llevar vidas plenas, felices y sobre todo dentro de la legalidad ${ }^{3}$.

Adjunto el testimonio de Ethan Edwards, codirector de la plataforma de apoyo a pedófilos Virtuous Pedophiles, al que escribí un email el 12 de agosto de 2017 invitándole a

\footnotetext{
${ }^{3}$ Argumento procedente de Virtuous Pedophiles, redactado por sus fundadores, Ethan Edwards y Nick Devin.
} 
dar su opinión acerca de las muñecas sexuales con rasgos infantiles. Seguidamente traduzco del inglés las partes más relevantes de su respuesta:

En primer lugar, entendemos que a muchos la idea de sentir atracción sexual hacia los niños les parece repulsiva -así es como todos hemos sido educados-, de modo que un rechazo instintivo a las muñecas es comprensible.

En segundo lugar, la cuestión de si dichas muñecas son legales o no es secundario para nosotros: nos importa mucho más no ser considerados monstruos por la sociedad, poder acudir a terapia con la seguridad de que no vamos a ser denunciados, y no perder nuestros trabajos o amigos si somos descubiertos. Las muñecas no suponen una gran diferencia positiva para nosotros, no más que las muñecas adultas lo harían para las personas normales. Una muñeca es muy diferente de una persona real.

En tercer lugar, personalmente tengo un fuerte compromiso con las libertades civiles. Me gustaría mantener al gobierno fuera de las habitaciones de las personas, especialmente cuando éstas se encuentran solas allí. Libros, películas, muñecas: no deberíamos censurarlas. No restringimos los libros que la gente puede leer basándonos en si podrían inspirarlos a hacer cosas malas. Las películas están llenas de violencia que no quisiéramos que nadie emulase en la vida real, mas no censuramos esas películas.

Finalmente, la gente quiere saber cuál sería el efecto general de las muñecas -si las muñecas están disponibles, ¿eso haría que los niños reales estuvieran más o menos seguros? - Los pedófilos, al igual que todo el mundo, son diferentes entre sí, y pueden reaccionar de forma distinta. Para algunos puede ser el estímulo que los lleve a abusar de niños en la realidad. A otros podría ayudarles a satisfacer deseos que de otra manera llevarían a cabo con un niño real. Pero tenemos algunos estudios muy interesantes:

Diamond de la Universidad de Hawaii y sus colegas han estudiado el caso de varios países donde la pornografía infantil estaba prohibida y de repente se volvió fácil de obtener. Lo que pasó es que el abuso a niños reales o bien se mantuvo o bien disminuyó. En ningún caso aumentó. Todo apunta a que con las muñecas sexuales con rasgos infantiles sucederá lo mismo. Los estudios de Diamond no sugieren que la pornografía infantil debería ser legal, pues se hace daño a los niños al producirla. Pero indican que la pornografía virtual podría tener efectos beneficiosos, y estas muñecas podrían ser consideradas como tales. 


\section{Conclusiones}

Los resultados de esta investigación nos permiten concluir que las muñecas sexuales con rasgos infantiles, consideradas como pornografía virtual en tres dimensiones, probablemente no producirían un aumento del riesgo de comisión de abusos sexuales a menores por parte de pedófilos.

En primer lugar, se investigó la relación entre pedofilia y abusos sexuales a menores, y se constató que no existe una relación directa entre ambos conceptos. Seto (2008) concluye que a pesar de que una gran parte de los que cometen abusos a menores son pedófilos, la pedofilia per se, definida como atracción sexual por individuos pubescentes o prepubescentes, no es causa de los mismos. Por otro lado, los individuos que abusan sexualmente de menores no difieren de los que abusan o agreden sexualmente a adultos (Whitaker et al, 2008). El riesgo de cometer abusos sexuales a menores vendría condicionado principalmente, como en el caso de los delitos en general, por la presencia de antecedentes delictivos, así como factores psicológicos, sociales y familiares; de modo que la presencia de las muñecas sexuales con rasgos infantiles probablemente no influiría positiva ni negativamente en la tasa de abusos sexuales a menores. Beier (2017) concluye que la diferencia entre los pedófilos que delinquen y los que no se basa en la capacidad de estos últimos para controlar sus impulsos.

En segundo lugar, se analizaron las características de las muñecas sexuales con rasgos infantiles, y se comprobó que se trata de muñecas anatómicamente correctas que representan a niñas y adolescentes de un mínimo de 5 años. Estas muñecas se utilizarían como sustituto del contacto sexual con menores, según atestiguan tanto el fabricante de las muñecas como sus clientes (Shin Takagi, citado por Morin, 2016).

En tercer lugar, se profundizó en la relación entre consumo de pornografía infantil y abusos sexuales a menores y se comprobó que no es significativa. Si se considera a las muñecas como un tipo de pornografía infantil virtual (representaciones de menores generadas artificialmente, en tres dimensiones), es probable que los resultados sean similares a los obtenidos en numerosos estudios sobre la relación entre el consumo de pornografía infantil y los abusos sexuales a menores por parte de pedófilos. 
El consumo de pornografía infantil no genera un incremento significativo del riesgo de cometer abusos sexuales a menores (Ekeet al, 2011; Endrass, 2009; Fisher et al, 2013). A gran escala, el estudio llevado a cabo por Diamond (2011) en la República Checa y replicado con éxito en otros países como Dinamarca o Reino Unido, muestra que no se ha podido comprobar la existencia de una relación entre consumo de pornografía infantil y abusos sexuales.

Finalmente, existen razones empíricas para considerar la pedofilia como una orientación sexual: la edad de aparición del interés sexual es similar en pedófilos, homosexuales y heterosexuales (Abel et al, 1987; Freund \& Kuban, 1993; Li, 1991; Marshall, Barbaree \& Ecles, 1991). al igual que sucede en el resto de orientaciones sexuales, la pedofilia es estable en el tiempo (Hanson et al, 1993) y los pedófilos no buscan sólo contacto sexual con menores, sino también relaciones románticas con ellos (Li, 1991; Wilson \& Cox, 1983). Considerar la pedofilia como una orientación sexual, como sugiere Seto (2012) supone asumir que las terapias reorientativas no serían capaces de alterar las preferencias de base (Drescher \& Zucker, 2006) de los pedófilos, por tanto, la clave para prevenir los abusos sexuales a menores se basaría en un adecuado control de impulsos por parte de estos individuos. Diamond (2011) sugiere que el material pornográfico producido virtualmente podría contribuir a canalizar dichos impulsos, y las muñecas sexuales con rasgos infantiles podrían ser consideradas como tales.

Los resultados del presente trabajo permiten concluir que probablemente la presencia de muñecas sexuales con rasgos infantiles no producirá un incremento del riesgo de comisión de abusos sexuales a menores por parte de pedófilos, aunque quedamos a la espera de la realización de estudios específicos con muñecas, en los que participen tanto pedófilos con antecedentes penales como aquellos sin un historial delictivo previo. Asimismo, sería conveniente la realización de estudios que evaluasen el impacto social que podría tener la permisividad de estas muñecas, ya que en la actualidad los casos en torno a este fenómeno suscitan una fuerte repulsión.

Una de las dificultades de este trabajo es que no se puede garantizar que las muñecas sexuales con rasgos infantiles tengan los mismos efectos que la pornografía, y que por tanto las conclusiones sobre ésta puedan extrapolarse a aquéllas. Otra limitación la constituye el

\section{Revista Española de Investigación Criminológica}


hecho de que para esta investigación se han tenido en cuenta principalmente como factores criminógenos los relativos al fenómeno delictivo, sin detenernos, por exceder del ámbito de este estudio, a cuantificar o valorar la alarma social que la permisividad de estas muñecas generaría en cada país y que podría contribuir en buena medida a justificar o no su prohibición.

De todas formas, antes de que los Estados tomen una decisión al respecto individualmente sería aconsejable la realización de los estudios recomendados por parte de instituciones científicas o universidades. Posteriormente, se recomienda la elaboración de informes por parte de expertos, que pudieran asesorar a los grupos políticos encargados de proponer iniciativas legislativas tanto a nivel nacional como a nivel europeo, dado que esta materia estaría excluida de la iniciativa legislativa popular y de la iniciativa ciudadana europea. En el caso de España, sería aconsejable que dichos informes estuviesen a disposición de los operadores jurídicos, principalmente jueces y fiscales, de modo que si se plantea un caso con muñecas sexuales con rasgos infantiles, como ya ha sucedido en otros países, éstos puedan contar con evidencias científicas que les ayuden a tomar una decisión fundamentada, ya sea en uno u otro sentido. 


\section{Referencias}

American Psychiatric Association. (2013). Diagnostic and Statistical Manual of Mental Disorders (5th ed.). Arlington, V.A: American Psychiatric Publishing

Abel, G., Becker, J., Mittelman, M., Cunningham-Rathner, J., Rouleau, J.L., \& Murphy, W.D. (1987). Self-reported sex crimes of non-incarcerated paraphiliacs. Journal of Interpersonal Violence, 2, 3-25. DOI: 10.1177/088626087002001001

All Dolled Up: Finnish Foundation Promotes Sex Dolls Against Child Abuse. (13 de marzo de 2017). Sputniknews. Recuperado de https://sputniknews.com/art_living/201703131051515438-sex-dolls-childabuse/?utm_source=short_direct\&utm_medium=short_url\&utm_content=dM9B\&ut m_campaign=URL_shortening

B4UACT. Recuperado dehttp://www.b4uact.org

Beier, K. (2015) The German Dunkenfeld Project: Proactive strategies to prevent child sexual abuse and the use of child abusive images. International Perspectives of Crime Prevention 7. Contributions from the 8th Annual International Forum 2014 within the German Congress on Crime Prevention Forum Verlag Godesberg GmbH 2015

Beier, K., Grundmann, D., Kuhle, L., Schemer, G., Konrad A., \& Amelung, T. (2015). The German Dunkelfeld Project: A Pilot Study to Prevent Child Sexual Abuse and the Use of Child Abusive Images. The Journal of Sexual Medicine, 12(2), 529-542.DOI: 10.1111/jsm. 12785

Beier, K., Kärgel, C., Massau, C., Weiß, S., Walter, M., Borchardt, V.,...Schiffer, B. (2017). Evidence for superior neurobiological and behavioral inhibitory control abilities in non-offending as compared to offending pedophiles. Human BrainMapping, 38(2), 1092-1104.DOI: $10.1002 / \mathrm{hbm} .23443$

Circular 2/2015 de la Fiscalía General del Estado sobre los delitos de pornografía infantil tras la reforma operada por LO 1/2015.

Ley Orgánica 10/1995, de 23 de noviembre, del Código Penal.

Chivers, M., Seto, M.\& Blanchard, R. (2007). Gender and sexual orientation differences in sexual response to the sexual activities versus the gender of actors in sexual films. Journal of Personality and Social Psychology, 93, 1108-1121. DOI: 10.1037/00223514.93.6.1108

Condrom, M. \&Nutter, D. (1988). A preliminary examination of the pornography experience of sex offenders, paraphiliacs, sexual dysfunction patients, and controls based on meese commission recommendations. Journal of Sex and Marital Therapy, 14(4), 285-298. DOI: 10.1080/00926238808403811

Diamond, L. (2008). Sexual fluidity: Understanding women's love and desire. Cambridge, M.A: Harvard University Press.

Revista Española de Investigación Criminológica

Artículo 9, Número 17 (2019)

www.criminologia.net

ISSN: 1696-9219 
Diamond, M., Jozifkova, E., \& Weiss, P. (2011). Pornography and sex crimes in the Czech Republic. Archives of Sexual Behavior 40, $1037 . \quad$ DOI: https://doi.org/10.1007/s10508-010-9696-y

Donelly, B. (14 de agosto de 2016). I Am an Artist: Man Who Makes Child Sex Dolls for Pedophiles. The Sidney Morning Herald.com.Recuperado de http://www.smh.com.au/national/i-am-an-artist-man-who-makes-child-sex-dollsfor-paedophiles-20160812-gqrlew.html

Don't Offend. Recuperado de https://www.dont-offend.org/

Drescher, J., \& Zucker, K. (2006)Exgay research: Analyzing the Spitzer study and its relation to science, religion, politics, and culture. Binghamton, NY: Haworth.

Eke, A., Seto, M., y Williams, J. (2011). Examining the criminal history and future offending of child pornography offenders: an extended prospective follow-up study. Law and Human Behavior, 35(6), 466-478.DOI: 10.1007/s10979-010-9252-2

Endrass, J., Urbaniok, F., Hammermeister, L., Benz, C., Elbert, T., Laubacher, A., \&Rossegger, A. (2009). The consumption of Internet child pornography and violent and sex offending. BMC Psychiatry, 14, 9-43.DOI:10.1186/1471-244X-9-43

Fighters Against Child Abuse Australia. (2015-2016). Child Sex Dolls are not a Game. Change.org. Recuperado de https://www.change.org/p/annastacia-palaszczuk-childsex-dolls-are-not-a-game

Fisher, W., Kohut, T., Di Gioacchino, L, \&Fedoroff, P. (2013). Pornography, sex crime and paraphilia. Current Psychiatry Reports, 15(6), 362.DOI: 10.1007/s11920-013-03627

Freund, K., \& Kuban, M. (1993). Toward a testable developmental model of pedophilia: The development of erotic age preference. Child Abuse and Neglect, 17, 315-324. DOI:https://doi.org/10.1016/0145-2134(93)90051-6

General, R. (28 de junio de 2017). British Man Jailed for Buying Pedophile Doll From Hong Kong. Nextshark.com. Recuperado de https://nextshark.com/british-man-jailedbuying-pedophile-doll-hong-kong/

Hall, R. (2007). A profile of pedophilia: Definition, characteristics of offenders, recidivism, treatment outcomes, and forensic issues. Mayo Clinic Proceedings, 82 (4), 457-471. DOI:10.4065/82.4.457

Hanson, R., Steffy, R.\& Gauthier, R. (1993). Long-term recidivism of child molesters. Journal of Consulting and Clinical Psychology, 61, 646-652.DOI: http://dx.doi.org/10.1037/0022-006X.61.4.646

Harris, M. (1994). Family Found: The Lifetime Obsession of Morton Bartlett. Gerngross \& Company, New York.

Hill, K. (14 de julio de 2014). Are Child Sex-Robots inevitable? Forbes.com. Recuperado de https://www.forbes.com/sites/kashmirhill/2014/07/14/are-child-sex-robotsinevitable/\#61dd597be460

Revista Española de Investigación Criminológica

Artículo 9, Número 17 (2019)

www.criminologia.net

ISSN: 1696-9219 
Knight, C. (2011). Less than Playful: Hans Bellmer's Doll Photographs as Archive and Artwork. Visual Resources, 27(3), 227-248.DOI: https://doi.org/10.1080/01973762.2011.597164

Li, C. (1991). 'The main thing is being wanted': Some case studies on adult sexual experiences with children. Journal of Homosexuality, 20, 129-143. DOI:10.1300/J082v20n01_09

Marshall, W., Barbaree, H., \& Eccles, A. (1991). Early onset and deviant sexuality in child molesters. Journal of Interpersonal Violence, 6, 323-336.

Morin, R. (11 de enero de 2016). Can Child Sex Dolls Keep Pedophiles from Offending? The Atlantic.com Recuperado de https://www.theatlantic.com/health/archive/2016/01/can-child-dolls-keeppedophiles-from-offending/423324/

Paradise, J. (2001) Current Concepts in Preventing Sexual Abuse. Current Opinion in Pediatrics, 13(5), 402-407.

Revesz, R. (14 de agosto de 2016). Canadian court to determine whether child sex doll constitutes child pornography. Independent $U K$. Recuperado de https://www.independent.co.uk/news/world/americas/canada-court-child-sex-dollpornography-paedophilia-newfoundland-kenneth-harrison-a7578321.html

Rutkin, A. (2 de agosto de 2016). Could Sex Robots and Virtual Reality Treat Paedophilia? Newscientist.com. Recuperado de https://www.newscientist.com/article/2099607could-sexrobots-and-virtual-reality-treat-paedophilia/

Seto, M. (2008)Pedophilia and Sexual Offending Against Children:Theory, Assessment and Intervention. Washington, DC: American PsychologicalAssociation

Sharkey, N., Van Wynsberghe., Robbins, S., \& Hancock, E. (2017). Our Sexual Future with Robots. The Hague, Netherlands:Foundation for Responsible Robotics.Recuperado de http://responsiblerobotics.org

Stop It Now!. Recuperado de https://www.stopitnow.org.uk/

Tansella, C. (2014). Morton Bartlett's Secret Dolls. Epidemiology and Psychiatric Sciences, 23, 129-131. DOI: 10.1017/S2045796014000134

Taylor, G. (2 de agosto de 2018). Further seizure of child sex dolls that resemble children. NorwayToday. Recuperado de http://norwaytoday.info/news/seizure-sex-dollsresemble-children

The Finnish Sexpo Foundation (1969).Recuperado de https://www.sexpo.fi/

Virtuous Pedophiles. Recuperado de https://www.virped.org/

Von Krafft-Ebing, R. (1886)Psychopatia Sexualis.F.A. Davis co, Philadelphia, London.

Whitaker, D., Le, B., Karl Hanson, R., Baker., C., McMahon, P., Ryan, G., Klein, A., \& Rice, D. (2008) Risk factors for the perpetration of child sexual abuse:A review and metaanalysis. Child Abuse \& Neglect, 32 (5) 529-548.DOI: 10.1016/j.chiabu.2007.08.005

Revista Española de Investigación Criminológica

Artículo 9, Número 17 (2019)

www.criminologia.net

ISSN: 1696-9219 
Wilson, G., \& Cox, D. (1983) The child-lovers: A study of paedophiles in society.London: Peter Owen.

\section{Agradecimientos}

Se agradece a la tutora del trabajo que originó este proyecto, Candela Gracia Morillo, y a los profesores Federico Pozo Cuevas, Salvador Cutiño Raya y Masako Nakahira, tanto las sugerencias y comentarios realizados, como los ánimos ofrecidos para darlo a conocer. Se agradece también a Ethan Edwards por su colaboración y amable interés en la investigación. Se agradece asimismo a la Sociedad Española de Investigación Criminológica (SEIC) por elegir este trabajo como finalista del Premio SEIC a Estudiantes de Criminología y permitir con ello que fuera presentado y discutido en el marco del XII Congreso Español de Criminología (Oviedo, 2018).

Mónica Montoro es graduada en Derecho y Criminología por la Universidad Pablo de Olavide en Sevilla. Ha asistido a numerosos congresos de Criminología, especialmente sobre Victimología y Perfilación Criminal. Sus temas de interés son los trastornos parafílicos y los delitos de carácter sexual. 